\title{
Virtual learning during the COVID-19 pandemic: a turning point in neurosurgical education
}

\author{
Nasser M. F. El-Ghandour, MD, ${ }^{1}$ Ahmed A. M. Ezzat, MSc, MD, ${ }^{1}$ Mohamed A. Zaazoue, MD, MSc, ${ }^{2}$ \\ Pablo Gonzalez-Lopez, MD, PhD, ${ }^{3}$ Balraj S. Jhawar, MD, MSc, DSc, FRCSC, ${ }^{4}$ and \\ Mohamed A. R. Soliman, MSc, MD ${ }^{1,4}$
}

\begin{abstract}
'Department of Neurosurgery, Faculty of Medicine, Cairo University, Cairo, Egypt; ${ }^{2}$ Department of Neurological Surgery, Indiana University School of Medicine, Indianapolis, Indiana; ${ }^{3}$ Department of Neurosurgery, Hospital General Universitario de Alicante, Miguel Hernandez University, Alicante, Spain; and ${ }^{4}$ Department of Neurosurgery, Schulich School of Medicine and Density, Western University, Windsor, Ontario, Canada
\end{abstract}

OBJECTIVE The coronavirus disease 2019 (COVID-19) pandemic has caused dramatic changes in medical education. Social distancing policies have resulted in the rapid adoption of virtual learning $(\mathrm{VL})$ by neurosurgeons as a method to exchange knowledge, but it has been met with variable acceptance. The authors surveyed neurosurgeons from around the world regarding their opinions about $\mathrm{VL}$ and how they see the future of neurosurgical conferences.

METHODS The authors conducted a global online survey assessing the experience of neurosurgeons and trainees with VL activities. They also questioned respondents about how they see the future of on-site conferences and scientific meetings. They analyzed responses against demographic data, regions in which the respondents practice, and socioeconomic factors by using frequency histograms and multivariate logistic regression models.

RESULTS Eight hundred ninety-one responses from 96 countries were received. There has been an increase in VL activities since the start of the COVID-19 pandemic. Most respondents perceive this type of learning as positive. Respondents from lower-income nations and regions such as Europe and Central Asia were more receptive to these changes and wanted to see further movement of educational activities (conferences and scientific meetings) into a VL format. The latter desire may be driven by financial savings from not traveling. Most queried neurosurgeons indicated that virtual events are likely to partially replace on-site events.

CONCLUSIONS The pandemic has improved perceptions of $\mathrm{VL}$, and despite its limitations, $\mathrm{VL}$ has been well received by the majority of neurosurgeons. Lower-income nations in particular are embracing this technology. VL is still evolving, but its integration with traditional in-person meetings seems inevitable.

https://thejns.org/doi/abs/10.3171/2020.9.FOCUS20634

KEYWORDS virtual learning; e-learning; teleconference; education; COVID-19; knowledge exchange

$\Lambda$ DVANCES in medicine are dependent on the effective exchange of knowledge. Traditionally, this has occurred through reading, testing, tutorials, problembased teaching, didactic lectures and seminars, hands-on clinical experiences, and, most recently, online learning. ${ }^{1}$ The coronavirus disease 2019 (COVID-19) pandemic has caused a seismic shift in the way we learn, and the impact is expected to be long-lasting. ${ }^{2}$

Most countries have suspended in-person medical education, conferences have been canceled or postponed, and teaching rounds and seminars have migrated from the classroom to the digital screen. The majority of medical learning, such as teaching rounds or conferences, is occurring virtually. ${ }^{3-8}$ Although this trend may not be indefinite, it will without a doubt change the way we learn.

This shift to virtual learning (VL) poses new challenges. Is online learning as effective and efficient as in-person communication? What are the limits to video conferencing when demonstrating clinical skills? Are questions and responses equally engaging when delivered through a microphone versus face-to-face? Much of this remains to be seen. Regardless, the shift to online education has taken a tremendous step forward and is not likely to regress.

Neurosurgeons have been quick to adapt to the new

ABBREVIATIONS AANS = American Association of Neurological Surgeons; CNS = Congress of Neurological Surgeons; COVID-19 = coronavirus disease 2019; VL = virtual learning; WFNS = World Federation of Neurosurgical Societies.

SUBMITTED July 10, 2020. ACCEPTED September 23, 2020.

INCLUDE WHEN CITING DOI: 10.3171/2020.9.FOCUS20634. 
paradigm of virtual education. The Congress of Neurological Surgeons (CNS) has granted free access to many of its educational resources. The World Federation of Neurosurgical Societies (WFNS), American Association of Neurological Surgeons (AANS), CNS, and Brazilian Society of Neurosurgery are rapidly producing new material for continuing medical education. ${ }^{9-12}$ The AANS, for the first time, recently replaced their on-site conference with a virtual meeting. ${ }^{12}$ The exceptional attendance inspired larger organizations to follow suit. ${ }^{8,13}$ The impact this will have on the future of the neurosurgical community is yet to be seen.

The majority of medical research has tended to occur in higher-income nations, and this has resulted in most conferences occurring in these nations as well. ${ }^{14,15}$ Unfortunately, attending meetings in these nations can be costly, which limits participation by attendees from lowerincome nations and thus creates barriers to progress for these nations. ${ }^{14}$

To better understand the benefits of online neurosurgical learning, we set out to survey the opinions of neurosurgeons around the world regarding their experiences with this new platform. We also sought their opinions regarding future insight into the impact of this technology on the on-site conferences and meetings.

\section{Methods}

We designed a questionnaire assessing neurosurgeons' behaviors and opinions related to VL. We asked participants to provide basic information about their practice and experience in neurosurgery, their behaviors regarding neurosurgical VL before and after the COVID-19 pandemic, their perception of the value of VL, and their opinions on how future VL should be incorporated into on-site conferences and meetings.

We obtained neurosurgeons' contact information from professional contact lists and social media forums (Facebook, Twitter, and WhatsApp) and through interpersonal contacts. We also utilized open-access social mediabased surveys through neurosurgery groups (Facebook and Telegram).

We distributed questionnaires (in English and Spanish), which we had created using Google Forms (Google LLC), from May 21, 2020, to June 4, 2020. For potential Chinese participants, we emailed portable document format (PDF) questionnaires.

Respondents were asked to declare their subspecialty. We categorized the respondents' residence by income and region according to the World Bank classification. ${ }^{12}$

This study was conducted in accordance with STROBE guidelines. ${ }^{16}$

\section{Statistical Methods}

Statistical analysis was done using SPSS version 26 (IBM Corp.). Participant responses were tabulated using frequency histograms. To analyze relationships between independent variables and outcomes, we used multivariable logistic regression to calculate odds ratios and 95\% confidence intervals and $p$ values. Significance was considered at $\mathrm{p}<0.05$.

\section{Results}

We received 266 responses from social media-based neurosurgery groups through Facebook, Twitter, and Telegram and 625 responses from 1029 Facebook Messenger, Twitter, WhatsApp, and email direct invitations (response rate, $60.7 \%$ ) for a total of 891 responses from 96 countries. Characteristics of the surveyed neurosurgeons are summarized in Fig. 1.

The vast majority of our respondents $(90.3 \%)$ had attended VL activities during the COVID-19 pandemic, and these activities were primarily organized by international societies (63.2\%; Fig. 2).

\section{Experience With VL Activities Since the Start of the COVID-19 Pandemic}

The majority of respondents told us that because of their VL experiences they would change aspects of their practice $(55.7 \%)$. They believed that VL activities improved their knowledge of the best evidence-based practice $(65.7 \%)$ and the level of care they provided to their patients (62.1\%). Most respondents told us that they would also consider alternative management plans for their patients based on the knowledge they had acquired from VL sessions (63.4\%) and that VL had helped them improve patient outcomes $(56.7 \%)$ and communicate better with professional colleagues (63.6\%). Furthermore, the majority of the respondents found that VL activities provided them with networking opportunities (58.4\%) and indicated that their participation in future learning activities would likely increase (69.7\%).

\section{Virtual and On-Site Meetings and Conferences}

Figures 3 and 4 show the opinions of respondents regarding future participation in VL. Respondents were more likely to increase their participation in the future if they were from Sub-Saharan Africa (OR 2.3, 95\% CI 0.68.8) as compared to North America. We also found that those who had participated in VL during the pandemic were more likely to be willing to do so in the future (OR $5.3,95 \%$ CI 2.7-10.5). However, academic versus nonacademic neurosurgeons (OR 0.7, 95\% CI 0.4-1.2) and primarily cranial versus general neurosurgeons (OR 0.6, 95\% CI 0.4-1) were less likely to be willing to participate in future VL activities. When we asked which subspecialty would not benefit from VL activities, $58.8 \%$ of respondents chose "none."

Those who recommended that VL replace all on-site neurosurgical meetings were from lower-income nations: low (OR 4.6, 95\% CI 2-10.6), lower-middle (OR 2.6, 95\% CI 1.4-4.7), and upper-middle (OR 1.9, 95\% CI 1.1-3.3) compared to high-income countries. European and Central Asian neurosurgeons (OR 2.5, 95\% CI 1.1-5.8) were also more likely to propose such recommendations than North American neurosurgeons.

Respondents who had paid a fee for VL activities during the COVID-19 pandemic (OR 3.4, 95\% CI 2.1-5.5), as compared to those who had not paid a fee, were significantly more likely to recommend that VL replace all on-site neurosurgical meetings.

When respondents were asked to what extent should 


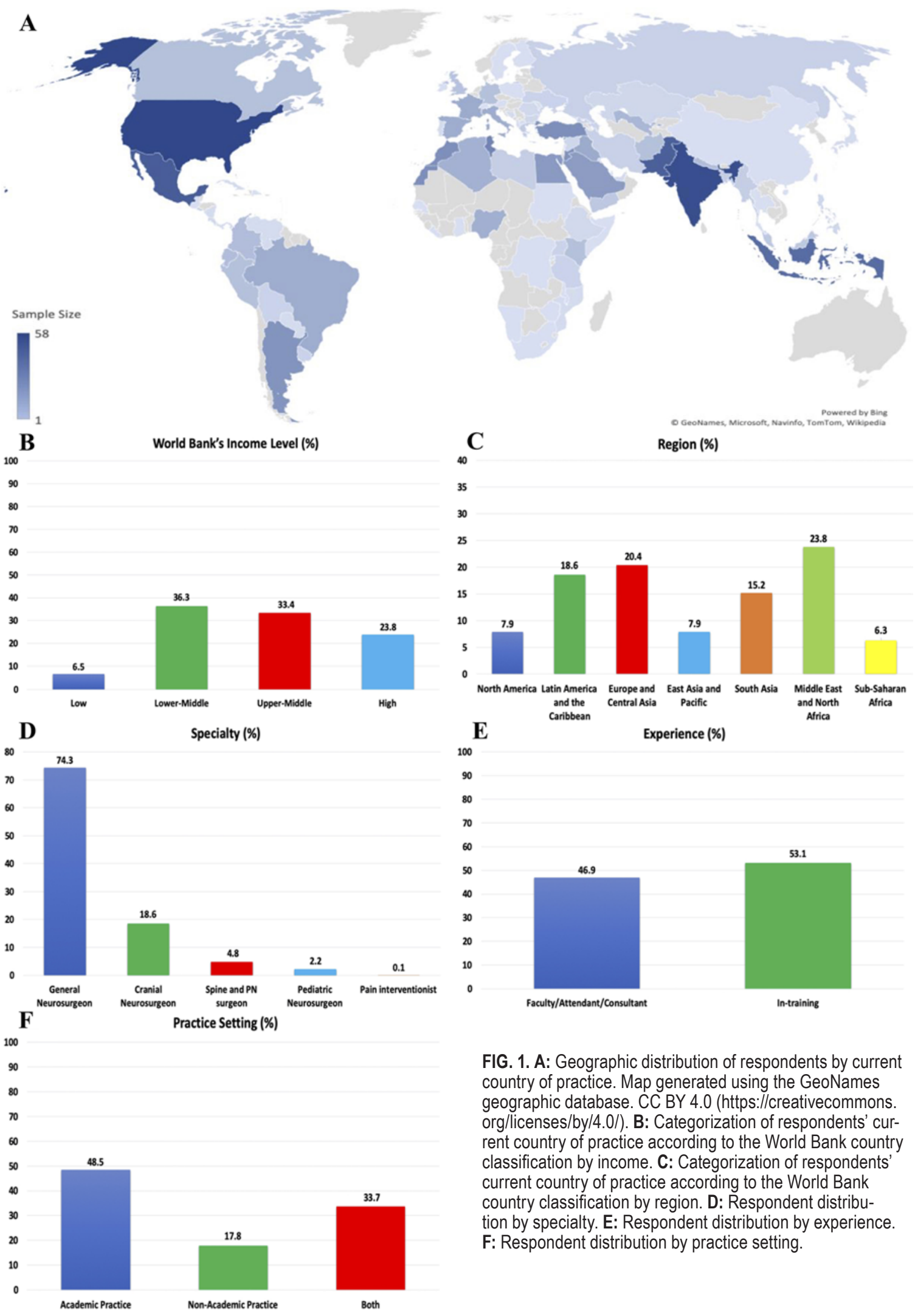


neurosurgical VL activities replace on-site meetings on a scale from 1 to 5 (1 indicating completely and 5 indicating not at all), our regression model showed that neurosurgeons from regions other than North America were more likely to indicate that virtual activities should completely replace on-site meetings. Similarly, neurosurgeons from low-income versus higher-income nations (OR 5.2, 95\% CI 0.6-43.7) and neurosurgeons who had paid a fee for VL activities during the COVID-19 pandemic versus those who had not paid a fee (OR 3.8, 95\% CI 1.6-9.3) were also more likely to support replacing on-site meetings.

Respondents were significantly more likely to attend an on-site conference virtually if they were in academic practice (OR 5.3, 95\% CI 1.9-14.8) or combined academic/nonacademic practice (OR 2.6, 95\% CI 1-6.7) than in nonacademic practice. However, faculty/attending/consultant respondents, as compared to in-training respondents, were less likely to attend such virtual conferences (OR 0.4, 95\% CI 0.2-1). This was also true for cranial (OR 0.3,95\% CI 0.1-0.9) and spine and peripheral nerve (OR 0.2, 95\% CI 0.1-0.7) surgeons compared to general neurosurgeons.

Predictors of those who would be willing to pay a fee for VL activities were being from Sub-Saharan Africa (OR 6.6, CI 1.8-24.3) versus North America and being a neurosurgeon who had not participated in VL activities before the current pandemic (OR 1.7, 95\% CI 1.2-2.4). On the contrary, neurosurgeons from low-income nations were significantly less likely to pay a fee for future VL activities than were those from high-income nations (OR $0.4,95 \%$ CI $0.2-0.9)$.

\section{Virtual Education and Training}

Most respondents believed that VL would change neurosurgical education but only partially replace on-site learning activities (Fig. 4). However, respondents from Europe and Central Asia (OR 0.5, 95\% CI 0.3-1) compared to North American respondents and respondents in academic practice (OR 0.6, CI 0.4-0.9) compared to those in nonacademic practice were less likely to believe that VL activities will alter neurosurgical training and education strategies in their country.

Many respondents believed that VL activities will alter neurosurgical training and education strategies in their region. This belief was far more likely among spine and peripheral nerve surgeons than general neurosurgeons (OR 2.7, 95\% CI 1.2-5.7) and among Sub-Saharan Africa neurosurgeons than North American neurosurgeons (OR 3, 95\% CI 1-8.8). Similar feelings were reported by faculty/ attendant/consultant respondents versus in-training respondents (OR 1.3, 95\% CI 1-1.8). Finally, neurosurgeons who had not participated in VL activities pre-COVID-19 (OR 1.4, 95\% CI 1-1.9) and those who had paid fees for VL activities since the start of the pandemic (OR 2.8, 95\% CI 1.6-5) also were more likely to believe that VL activities will alter neurosurgical training and education strategies in their country.

\section{Discussion}

Physicians acquire clinical knowledge primarily in practice but also by reading and interacting with others.
Workshops, symposia, and conferences have historically been the primary method by which this exchange has occurred. ${ }^{17}$ Even prior to the COVID-19 pandemic, staying abreast of the latest developments in practice has been challenging given time restrictions and difficulty accessing high-quality information. Conference attendance, for example, is very much driven by personal schedules, geography, and available finances.

Once the COVID-19 pandemic was officially declared, medical conferences were canceled or postponed worldwide, resulting in an almost complete cessation of in-person medical information exchange. This included the cancellation of the annual meetings of the AANS, CNS, WFNS, and The Society of Neurological Surgeons. ${ }^{6-8,18}$ Almost immediately, a seismic shift to VL as a method of continued interaction accelerated forward. Associations that already had prior experience with VL, such as the AANS and CNS, were able to move forward more quickly. ${ }^{19,20}$

The elimination of geographical distance as a barrier to attendance combined with the generally reduced costs of such activities attracted new audiences to VL activities and dismantled misperceptions of reluctant participants. Although there have been challenges to this transition, attendance at VL activities has been steadily rising. The paradigm shift has also created new venues for participation, such as the Virtual Visiting Professor by the CNS and the open-access online lecture series by the AANS., ${ }^{9,12}$ Also, there has been a significant increase in online subscriptions to free resources such as The Neurosurgical Atlas during this pandemic. ${ }^{21}$

Neurosurgical education has the additional challenge of having to teach complex psychomotor skills. Traditionally, this has been performed in hands-on cadaver labs and at vendor exhibits where attendees are able to explore the latest innovations with expert supervision. VL at this time cannot provide such experiences and thus has limitations. But in the future, this aspect will likely change as new technologies such as virtual reality, augmented reality, and $3 \mathrm{D}$ printing become available. ${ }^{22-24}$

\section{Experience With VL Activities Since the Start of the COVID-19 Pandemic}

In a recent Cochrane review, VL was found to provide little or no benefit over traditional learning with regard to knowledge acquisition, skills, and patient-related outcomes. ${ }^{25}$ This finding was not in keeping with the opinion of the majority of our respondents, who were willing to change their clinical practice based on their VL activities. Our respondents also reported an improvement in their knowledge of the best evidence-based practices and in the level of care that they provided to their patients. They also reported that they were more aware of alternative management plans and believed that they had a greater likelihood of achieving better patient outcomes.

The majority of respondents $(78.3 \%)$ indicated that their participation in VL activities had increased since the start of the COVID-19 pandemic in line with the increase in the availability of such activities. ${ }^{9}$ Additionally, $69.7 \%$ said they would increase their future participation in these events based on their experiences, indicating a general acceptance of VL among the neurosurgical community. 


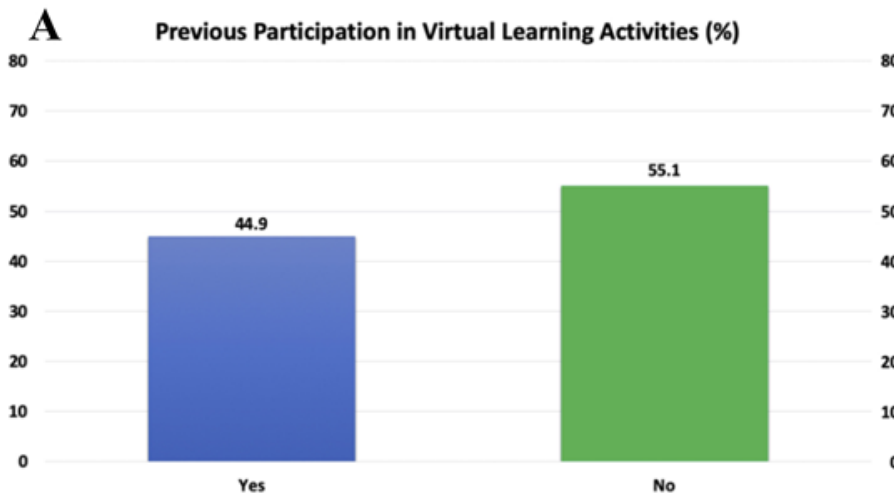

C Virtual Learning Activities Attendance Since the Start of
COVID-19 (\%)
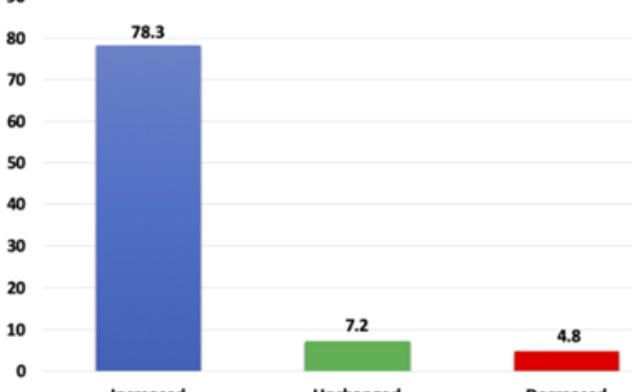

The Distribution of the Attended Virtual Learning Activities by
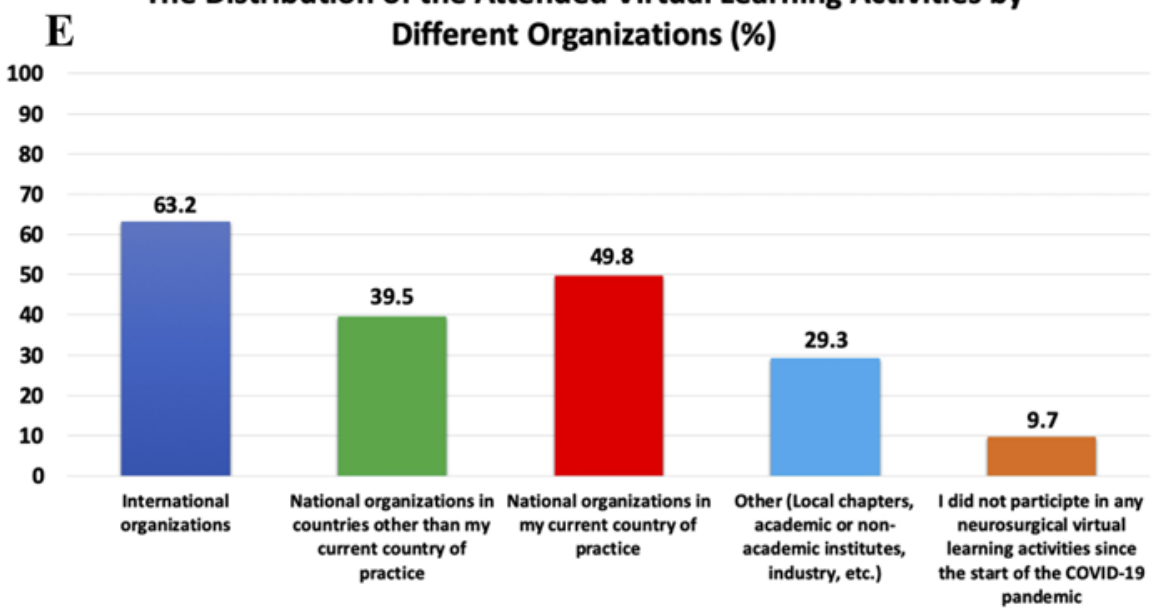

FIG. 2. A: Frequency of participation before the start of the COVID-19 pandemic. B: Proportion of respondents who attended a paid activity before the start of the COVID-19 pandemic. C: Frequency of participation since the start of the COVID-19 pandemic. D: Proportion of respondents who attended a paid activity since the start of the COVID-19 pandemic. E: Distribution of attended $\mathrm{VL}$ activities sponsored by different organizations.

\section{Virtual and On-Site Meetings and Conferences}

There was great interest in VL activities by respondents from low-income regions like Sub-Saharan Africa. The pandemic has provided new learning opportunities that were not previously available. Although many of these activities have been free or relatively inexpensive, the savings in travel expenses has made even events with fees attractive for individuals with fewer financial resources.

We found some reservations toward greater adoption of VL activities among academics, who seemed to have a

\section{B}

Paying a Fee in Virtual Learning Activities Before COVID-19 (\%)

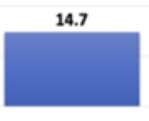

Yes

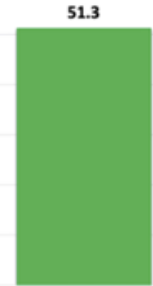

No

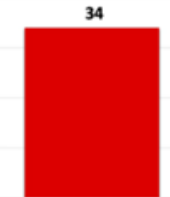

I did not Participate

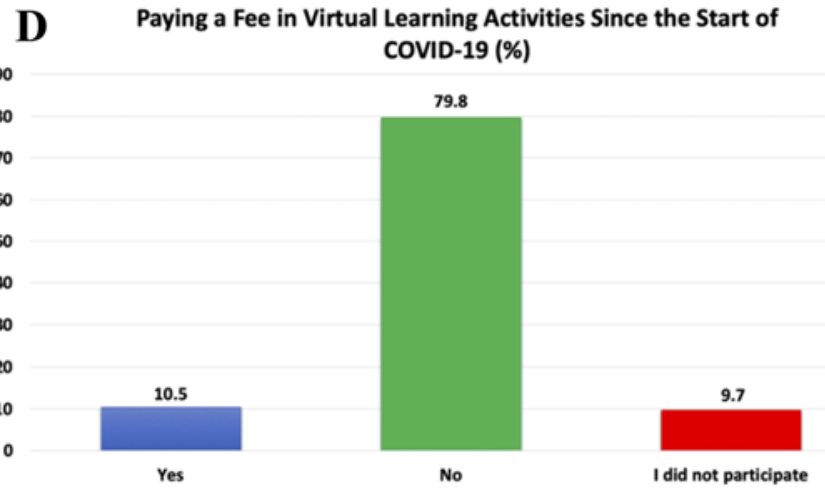

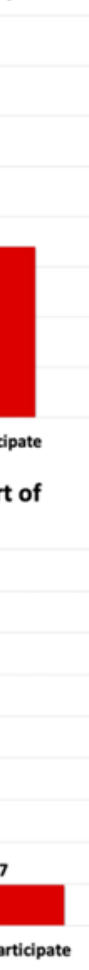




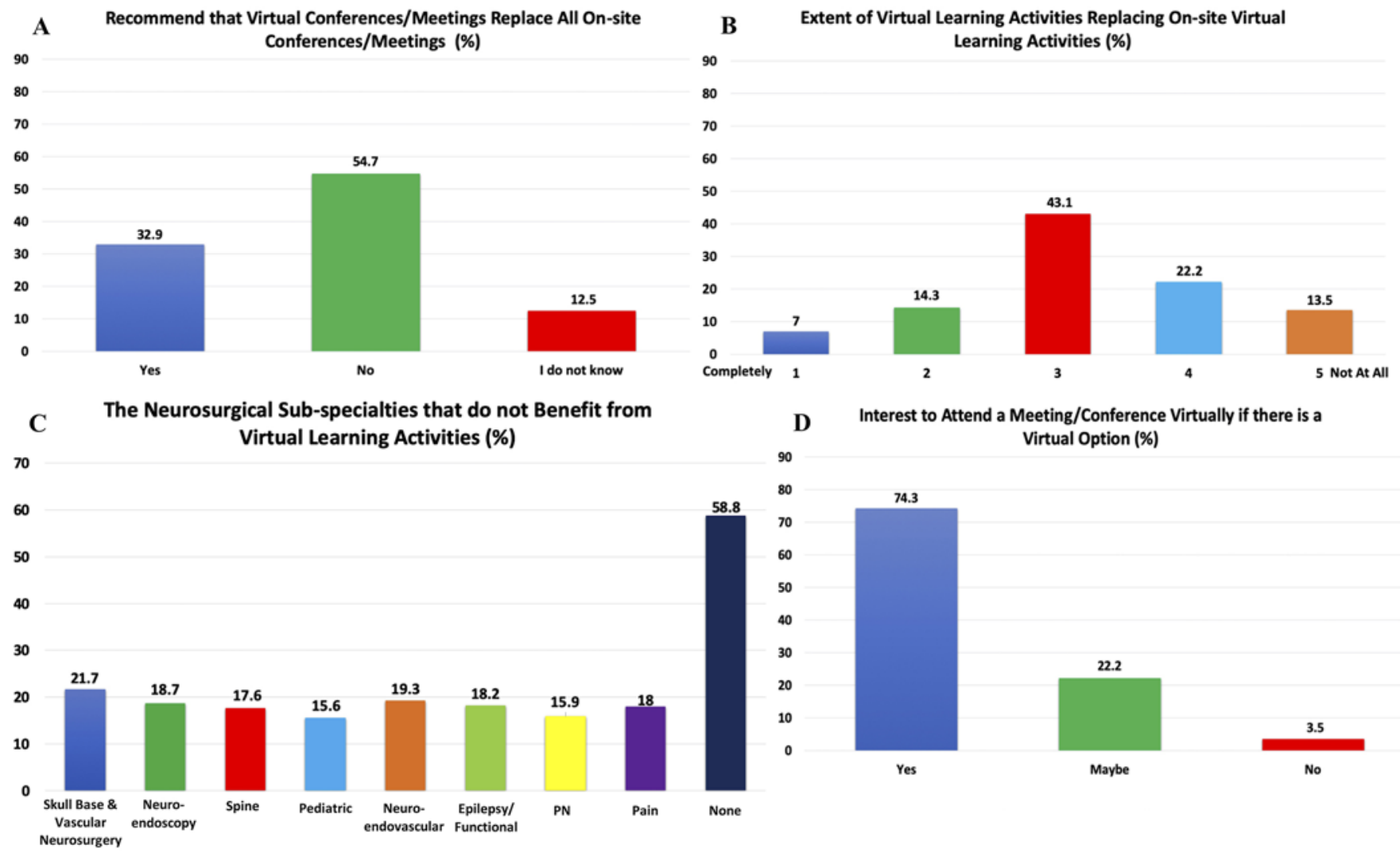

FIG. 3. A: Proportion of respondents who would recommend replacing all on-site neurosurgical conferences and meetings with virtual conferences and meetings. B: Respondent opinions on the extent to which neurosurgical VL activities would replace on-site neurosurgical learning activities. C: Respondent opinions on the neurosurgical subspecialties that would not benefit from neurosurgical VL activities. D: Proportion of respondents interested in attending neurosurgical conferences and meetings virtually, if there were an option for virtual attendance.

provide hands-on training. This may change in the future as simulation technology and virtual reality advance in the neurosurgical field..$^{20}$

Perhaps of even greater concern regarding VL is credibility. As the corpus of knowledge online expands, less reliable and sometimes inaccurate sources are becoming prevalent. This can lead to misinformation. ${ }^{26}$ Consequently, it is necessary for participants to be critical of their sources of VL. This is where established organizations have the advantage of being able to curate learning activities that can be trusted and being efficient in their ability to educate.

VL is also limited by internet access. Broadband reliability varies around the world and can even be a challenge in some higher-income nations. Poor connectivity in lower-income nations and Sub-Saharan Africa can result in poor sound or video quality, disconnection, question and answer overlap, and long lag times between questions and responses. ${ }^{27}$ Also in Sub-Saharan African nations, the cost of internet connectivity can be as much as fifty times higher than similar internet speeds in Europe. ${ }^{27,28}$ Organized neurosurgery is trying to address some of these issues - the Global Neurosurgery Initiative, for example, is trying to introduce high-quality neurosurgical education to these nations..$^{29}$ This will make them less dependent on the upcoming fifth-generation $(5 \mathrm{G})$ wireless technology that is expected to have a major impact on the future of the telecommunication of education and healthcare. ${ }^{30}$

Respondents from European and Central Asian regions were in favor of completely replacing on-site conferences and meetings with VL activities. This is probably financially motivated but may also be related to geographical distance from North America, where a large number of meetings tend to occur. Other authors have also found similar responses in low-income nations. ${ }^{31}$ Traditionally, participation by lower-income nations at major scientific meetings has been poor. ${ }^{14}$

Although organizers have reduced registration fees for these participants, the major barrier remains travel and accommodation costs. Schott et al. estimated that the cost of attending a conference in one's own country is $\$ 1424$, and this would be doubled if the attendee traveled to another continent. ${ }^{32}$ Support to attend conferences has been provided at the organizational level, such as through the WFNS Young Neurosurgeon grants, but overall participation is still limited..$^{33}$ Otherwise, participation in international meetings has largely been provided at the departmental level or through personal means.

Furthermore, recommendations that virtual conferences and meetings completely replace on-site conferences and meetings were more likely to be made by European and Central Asian neurosurgeons, increased participation 


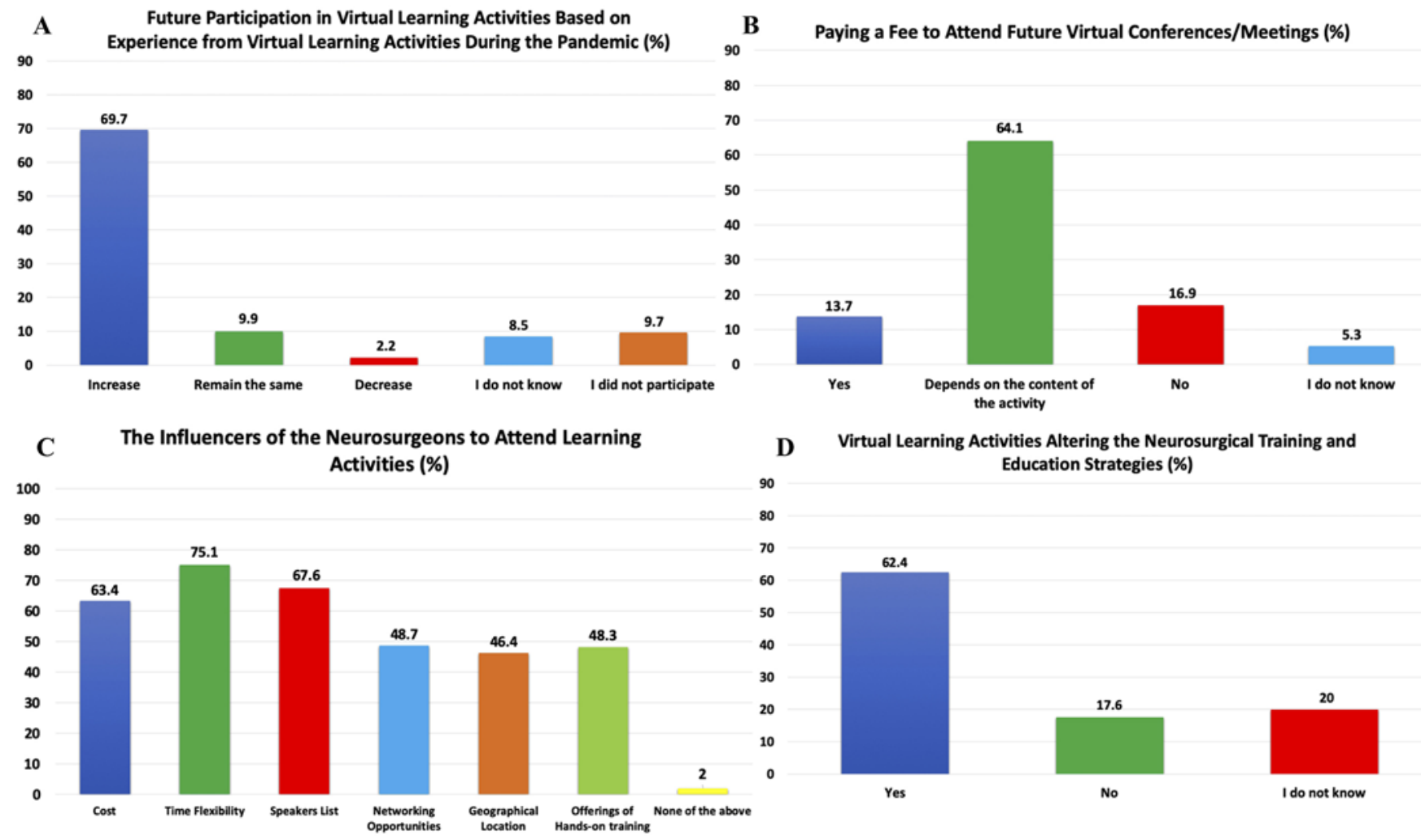

FIG. 4. A: Likelihood of future participation in neurosurgical VL activities based on respondent experience with the neurosurgical VL activities they attended during the COVID-19 pandemic. B: Likelihood of paying a fee in the future to attend any neurosurgical VL activities. C: Factors affecting the decision to participate in any type (virtual or on-site) of neurosurgical learning activity. D: Respondent opinions on whether neurosurgical VL could alter neurosurgical training and education strategies in their current country of practice.

in VL activities during the pandemic and paying a fee for VL activities, and were less likely by neurosurgeons from high-income nations. This might reflect the paucity of attendance at on-site meetings by neurosurgeons from lowincome countries because of the traveling and registration expenses.

Moreover, a number of reputable on-site meetings are organized in high-income countries, where a neurosurgeon's income is higher. Both factors would make it easier for neurosurgeons in these countries to attend on-site meetings within their geographical region or to be able to afford travel expenses to attend events of interest in other countries. ${ }^{7,8,34}$ However, it was surprising that neurosurgeons who had increasingly participated in VL activities were less likely to recommend VL replacement of all onsite meetings. This may be due to the drawbacks of VL activities that they had found through participation, such as the difficulty of interacting with the different participants, the impossibility of networking in prerecorded events and the less efficient networking during live events, and even the challenge of occasional technical issues, especially with the use of the more advanced technology required for virtual reality or in countries in which access to a stable high-speed internet connection is inconsistent. It is expected that there will be a learning curve until the most efficient setup for virtual events is established.

It seems that as we move forward, the option to virtu- ally attend conferences and meetings will likely become more common. We found that there was great interest in this option among neurosurgeons in academic practice or combined (academic and nonacademic) practice compared to those in nonacademic practice and among in-training respondents compared to faculty/attendant/consultant respondents.

Neurosurgeons from Sub-Saharan Africa were willing to pay a fee to attend VL conferences, but those from lowerincome nations were not. This likely reflects limited financial resources, and neurosurgery organizations may have to consider further reducing fees for this group of nations.

\section{Future Directions}

$\mathrm{VL}$ is in a renaissance period as we meet the challenges of the COVID-19 pandemic. We anticipate many changes ahead as this new educational platform evolves to meet the needs of our global neurosurgical community. Innovation in VL activities such as virtual reality platforms, ${ }^{24}$ virtual operating room live series, ${ }^{21}$ augmented reality, ${ }^{35}$ and simulation labs ${ }^{36}$ will contribute to the increased adoption of VL. Ultimately, VL will find its place in the way neurosurgeons transfer their experience to the next generation.

\section{Conclusions}

Our survey demonstrated a varied acceptance of VL as 
a new method of knowledge transfer. Although the majority of our respondents are now willing to embrace this new medium, some have reservations about its overuse. The COVID-19 pandemic has forced neurosurgeons to reconsider the way in which we share knowledge, and the impact is likely to be long-lasting. Ultimately, a balance will be achieved between VL and hands-on or traditional on-site conferences. The cost savings of VL, combined with increased accessibility for distant geographical audiences and those with fewer resources, cannot be ignored. Integrating VL into the neurosurgical curricula will increase information dissemination and improve care overall.

\section{Acknowledgments \\ Dedication}

To our brothers and sisters who have fallen to this invisible enemy. As we write this article, hundreds of physicians throughout the world have died at the frontlines fighting the COVID-19 infection. In these unprecedented times, our thoughts, actions, and prayers are with them and their families.

\section{Major Contributors (arranged according to their contribution)}

Reem Elwy, Sameh Elmorsy, Maher El Masry, Amany Ahmed, Mohamed Akl, Soraia Sousa, Maria Cahua, Abdullah F. Alkhamees, Ismail Bozkurt, François Lechanoine, Sophie d'Herbemont, Weaam Masoud, Wladimir Cárdenas, Khalif Abdifatah, Fernando Oviedo P., Emmanuel Sunday, Muhammad Khan, Abdelhafidh Slimane, Fah Bouare, Shavkat Rasulov, Edgar G. Ordóñez-Rubiano, Noor ul Huda Maria, Rupesh Raut, Yacine Felissi, Hafedh Jemel, Hamed Shinwari, Alexandrina Nikova, Zolo Yvan, Kais Maamri, Wael Alfaqaawy, Badr Arjdal, Ali Qubilat, Zakia Zakou.

\section{Contributors (alphabetical order, by first name)}

A. Zeidan, Abasin Aziz, Abbas Alnaji, Abdalla Morsy, Abdul Hafeez, Abdulaleem Sofian, Abdulgadir Bugdadi, Abedalkhalek Mohammed, Abid Houssem, Abrar Khan, Achal Gupta, Adegboyega Adebayo, Adel Alamery, Adel Mousavi, Adi Sulistyanto, Adil Belhachmi, Adisak Tanpun, Aditya Wicaksana, Agguini Dyhia, Ahlam Mustafa, Ahmed Al-Jradi, Ahmed Albayar, Ahmed Alhijji, Ahmed Alkalil, Ahmed AlMenabbawy, Ahmed Belal, Ahmed Cheema, Ahmed ElGhamry, Ahmed Khandaqgee, Ahmed Najem, Ahmet Özak, Ahsan Raza, Ahtesham Khizar, Ajid Risdianto, Akouete Martial, Ala Belhaj, Alaa Montaser, Alexander J. Schupper, Alfonso Ortiz, Ali Ahmed, Ali Akram, Alqroom Rami, Alvin Nah Doe, Amaury De Barros, Amend Ramesh, Amin Bizhan, Amine Adraoui, Amir Sohail, Amit Ghosh, Amit Pothare, Amr Hasanain Amr Mohamed, Ana Flor, Anan Shtaya, Ancuta Negru, Andi Sendjaja, Andrea Ortiz, Andrew Huh, Ankur Patni, Anssse Mejdoubi, Anthony Melot, Antonio Martínez, Anuvrat Sinha, Ariel Bravo, Armando Yaruro, Arnaud Lazard, Asad Shah, Ashish Sharma, Ashrapov Jamshid, Asim Andrabi, Augusto Alberto, Ayman Alshayji, Ayman Kelany, Azimullah Atrafi, Bader Jaafar, Bahtiar Adinoto, Bair Ginting, Bala Rajasekhar, Baris Saygili, Basheer Almoayana, Bassam Fallatah, Behzod Naimov, Beverly Cheserem, Bikramaditya Sah, Bintang Fernando, Bipin Chaurasia, Blind Al Talabani, Boniface Kivevele, Boon Liew, Borys Arbelaez, Boumehdi Hajar, Brahim Kammoun, Brijesh Panchal, Bruno Costa, Çağhan Tönge, Caio Prins, Camila Ahmed, Carlos Azabache, Carlos Erosa, Carlos Flores, Carlos Llobregat, Carlos Patiño, Carolina Cantarero, Centery Lee, Chiazor Onyia, Christian Beta, Chudy, Chun-Yu Cheng, Claire Karekezi, Cristian Gragnaniello, Cristina Aldea,
Cristina Gómez, Daniel Orozco, Daniel R. Babbu, Danielle Dang, David Tenelema, David Zumztein, Davron Kadyrov, Dawoud Khattab, Deepak P, Denis Ivliev, Devasheesh Kamra, Dewa Wardhana, Dexter Dimaano, Dhiman Chowdhury, Diana Lorena, Diego Quillo, Diego Rubio, Dikpal Singh, Dilli Pratama, Dilnoza Ruzieva, Diptiranjan Satapathy, Dmytro Shchybovyk, Dody Priambada, Domenico Catapano, Domenico Solari, Edward Jolayemi, Ehanga Marcel, Eka Satyawardhana, Elena López, Elkahla Ghassen, Elshan Huseynzade, Emmanuel de Schlichting, Emmanuel E. Albano Jr., Endris Hussen, Eng Tah Goh, Enrique Coritza, Enrique Luna, Ericko Laymena, Espinosa Fernando, Essam Youssef, Esteban Higuera, Evan Ozz, Fahd Abdel Sabour, Faisal Alabbas, Fathallah Elagori, Fayçal Lakhdar, Fernando Castro, Fernando Contreras, Fernando Pitti, Festus Susilo, Firman Muharam, Florian Bernard, Francisco Henriquez, Francisco Mannará, Francois Yves Legninda Sop, Frankie Siangshai, Franklin Fomekong, Frederic Wanis, Gabriela García, Gabriela Silva, Gerald Mayaya, Gerardo Taylor, Ghassen Gader, Ghislaine Gómez, Gionathan Amante, Giovanni Raffa, Giuseppe Raudino, Giuseppe Umana, Gopal Kundu, Gurupadappa Parappanavar, Hadi Shirzad, Hafedh Jemel, Hafsa Kara-Mostefa, Hakkou Elmehdi, Hamad Swideq, Hamzeh Albadawi, Hamzeh Alkhawaldeh, Hanan AlJohani, Harshal Agrawal, Hassan Almenshawy, Hesham Montaser, Himanshu Kumar, Houissa Sobhy, Hrushikesh Kharosekar, Htet Kyaw, Husam AbuKhedeir, Hussnain Tahir, Iago Tsertsvadze, Ibrahim Almamo, Ifeanyi Iwuagwu, Ilham Ernawan, Imad Ahmad, Irfan Ali, Isabel Arroteia, Isai García, Ivan Todorov, Jaime Lopez, Jamilton Lovo, Jan Detran, Javier Bellido, Jaweed Mohammad, JC HGQ MX, Jeffrey Raskin, Jeneral Alfin, Jhon Abello, Jiasheng Seet, Joel Aguilar, José Chang, José Martínez, Joshan Neupane, Juan Bargés, Juan Gabriel, Juan Pablo, Juan Paz, Juan Sales, Julio Delgado, Kaisar Haroon, Kamoliddin Pirnazarov, Karla Pedroza, Kennedy Kimani, Khabibullo Khasanov, Khaldoun Alsaboni, Khalif Abdifatah, Khalil Ayadi, Khoula Azmat, Kyaw Aung, Kyle Swanson, Lakshmi Narayana, Lamyae Eddarraz, Leila Da Roz, Leonardo Chacon, Leonardo Soto B., Louis-Marie Terrier, Lowton, Luis Ordonez, Luiz Alves, Lukman Hadi, Lydia Nanjula, Mabel Banson, Mahi Asmaa, Mahmoud Aboelsaad, Mahmoud Ben Messaoud, Manas Prakash, Maram El-Sadek, Marco Jiménez, Marcos Kehrwald, Marcos Vélez, Marcos Vilca, Mariano Rinaldi, Megan Still, Mehreen Mehboob, Mengistu Ayele, Mian Iftikhar, Mirna Sobana, Mirza Aditya, Moez Moussa, Mohamed Ellabbad, Mohamed Elmaghrabi, Mohamed Fouad, Mohamed Taieb, Mohamed Wehlie, Mohamed Youssef, Mohammad Baraka, Mohammad Elbaroody, Mohammad Rakib-Ul-Haque, Mohammad Sarwar, Motasem Khawaldeh, Mouguina Ilyas, Moysi Foteini, Muhammad Azhary, Muhammad Naeem, Muhammad Tariq, Musadique Latif, Mustafa K. Baskaya, Mutahar Al-Haddad, Mutembei Itunga, Mynzhylky Berdikhojayev, Nabi Abdullaev, Naing Lin, Nashaddin Mohammed, Nayda Panova, Nery Giler, Nibras AlSumaidaee, Nicat Mushtagov, Nicolas Sampron, Nikunja Yogi, Norma Sanchez, Noureddine Tebib, Nourou Dine Adeniran, Noussaiba Malhabi, Nur Muhammad, Nyail Chol, Obaid Rehman, Oles Garashchuk, Oludotun Ogunsola, Omar Qatawneh, Ondokuz Mayis, Oscar Servín, Othman Abdallah, P. Carrion, Patricio Manzone, Paulo Santa Maria, Pedro Gobbato, Pedro Góes, Peter Yustian, Piiamaria Virtanen, Pınar Ural, Prabu Rau Sriram, Pragnesh Bhatt, Prakash Kafle, Raju Venkatesh, Rajya Lakshmi, Rakhmon Egamberdiev, Ram Chandra Shrestha, Ramzi AlSharjpi, Ranjit Kumar, Raxmatov Karim, Rendy Badri, Rene Garcia, Renindra Ananda, Ricardo Bermúdez, Ricardo Maldonado, Rifi Loubna, Rihab Ben Fredj, Robert Kaduyu, Robert Tengar, Robin Bhattarai, Rolando Ollervides, Rosales Amaya, Rushikesh Gadhavi, Said Ait Benali, Saiful Hoque, Salah Alakkad,Salvador Mattar, Samaila Timothy, Samiu Okpara, Samuel Akinola, Samuel Moura, Sandeep Kumar, Sandrine de Ribaupierre, Sarmad Alkarawi, Sathyanarayana Lale, Satish 
Nayak, Scott Mitchell, Scott Shapiro, Sebastián Delgado, Sebastian Lopez, Selfy Oswari, Serhii Danchuk, Shahram Sherkat, Shaiq Rana, Shams Ud Din, Shashwat Mishra, Shavkat Rasulov, Shelly D. Timmons, Shiar Mustafa, Sidharth Agarwal, Şirzat Bek, Sofiene Bouali, Sokhib Saidov, Soliman Alborihi, Solomon Tuunde, Subbiah Thiruppathy, Sudhir Suggala, Syed Zaman, Taimoor Anwar, Tan Bih Huei, Tan Zi Han, Tarek Rayan, Tay Zar Win, Timechbache Abdenacer, Tochukwu Mbanugo, Toivo Hasheela, Tushit Mewada, Tze yu Yeh, Ucha Bobokhidze, Ujhelly Jose, Ulrick S. Kanmounye, Valeriy Cheburakhin, Vasileios Apostolopoulos, Veronica Martinez, Vikram M., Vikrant Keshri, Vincenzo Testa, Vlad Hufana, Vusal Mehman, Wafa Sohail, Walid Bennabi, Walid Elshamy, Wamedh Matti, Wasif Malik, Weaam Masoud, Wefaq Ullah, Wladimir Puya, Yahia Elbadri, Yarsi Astri, Yasir Hamandi, Yassin Sharif, Yassine Arrad, Yelimer Caucha, Yemisirach Akililu, Z. Hussain, Zain Iqbal, Zainab Sarwar, Zakia Ganoun, Zayya Naung, Иван.

\section{References}

1. Sahu PK, Chattu VK, Rewatkar A, Sakhamuri S. Best practices to impart clinical skills during preclinical years of medical curriculum. J Educ Health Promot. 2019;8:57.

2. McKee M, Stuckler D. If the world fails to protect the economy, COVID-19 will damage health not just now but also in the future. Nat Med. 2020;26(5):640-642.

3. American Medical Association. COVID-19: how the virus is impacting medical schools. Accessed October 22, 2020. https://www.ama-assn.org/delivering-care/public-health/ covid-19-how-virus-impacting-medical-schools

4. Liang ZC, Ooi SBS, Wang W. Pandemics and their impact on medical training: lessons from Singapore. Acad Med. 2020; 95(9):1359-1361.

5. Mian A, Khan S. Medical education during pandemics: a UK perspective. BMC Med. 2020;18(1):100.

6. Lewis CT, Zeineddine HA, Esquenazi Y. Challenges of neurosurgery education during the coronavirus disease 2019 (COVID-19) pandemic: a U.S. perspective. World Neurosurg. 2020;138:545-547.

7. American Association of Neurological Surgeons. Cancelled: 2020 AANS Annual Scientific Meeting. Accessed October 2, 2020. https://www.aans.org/en/Annual-ScientificMeeting/2020

8. Congress of Neurological Surgeons. 2020: annual meeting update. Accessed October 22, 2020. https://www.cns. org/2020-annual-meeting-update

9. Congress of Neurological Surgeons. Complimentary online education. Published June 10, 2020. Accessed June 9, 2020. https://www.cns.org/onlineed

10. World Federation of Neurosurgical Societies. Webinarsclinical resources. Published June 10, 2020. Accessed October 22, 2020. https://www.wfns.org/menu/78/webinars

11. SBN-Sociedade Brasileria de Neurocirurgia. Accessed October 22, 2020. https://portalsbn.org/

12. AANS Virtual 2020. Accessed October 22, 2020. https:// www.aans.org/virtual2020

13. Rutgers Biomedical and Health Sciences. Global neurosurgery: ask not for whom the bell tolls. Accessed October 22, 2020. https://rutgers.cloud-cme.com/default. aspx? $\mathrm{P}=5 \& \mathrm{EID}=3801$

14. Arend M-E, Bruijns SR. Disparity in conference registration cost for delegates from low- and middle-income backgrounds. Afr J Emerg Med. 2019;9(3):156-161.

15. Bruijns $\mathrm{S}$. Emergency medicine publication impact and habits between different world regions. F1000 Res. 2016;5:1139.

16. von Elm E, Altman DG, Egger M, et al. Strengthening the Reporting of Observational Studies in Epidemiology (STROBE) statement: guidelines for reporting observational studies. BMJ. 2007;335(7624):806-808.
17. Downes SR, Lykina T. Closing the gap in global neurosurgical education via online conference: a pre-covid survey. $\mathrm{Cu}$ reus. 2020;12(5):e8015.

18. Society of Neurological Surgeons. Accessed October 22, 2020. https://www.societyns.org/meetings/past-meetings

19. Bambakidis NC, Tomei KL. Editorial. Impact of COVID-19 on neurosurgery resident training and education. J Neurosurg. 2020;133(1):10-11.

20. Dedeilia A, Sotiropoulos MG, Hanrahan JG, et al. Medical and surgical education challenges and innovations in the COVID-19 era: a systematic review. In Vivo. 2020;34(3) (suppl):1603-1611.

21. Tomlinson SB, Hendricks BK, Cohen-Gadol AA. Editorial. Innovations in neurosurgical education during the COVID-19 pandemic: is it time to reexamine our neurosurgical training models? J Neurosurg. 2020;133(1):14-15.

22. Klein GT, Lu Y, Wang MY. 3D printing and neurosurgery-ready for prime time? World Neurosurg. 2013;80(3-4): 233-235.

23. Mitha AP, Almekhlafi MA, Janjua MJJ, et al. Simulation and augmented reality in endovascular neurosurgery: lessons from aviation. Neurosurgery. 2013;72(suppl 1):107-114.

24. Schirmer CM, Mocco J, Elder JB. Evolving virtual reality simulation in neurosurgery. Neurosurgery. 2013;73(suppl 1): 127-137.

25. Vaona A, Banzi R, Kwag KH, et al. E-learning for health professionals. Cochrane Database Syst Rev. 2018;1:CD011736.

26. Hughes MA, Brennan PM. The Internet for neurosurgeons: current resources and future challenges. Br J Neurosurg. 2011;25(3):347-351.

27. Paygar A. Challenges and opportunity of online learning in developing countries with specific focus on Liberia. Published 2014. Accessed October 22, 2020. https://www. bemidjistate.edu/academics/departments/political-science/ wp-content/uploads/sites/40/2015/05/paygar-thesis.pdf

28. Stienen MN, Schaller K, Cock H, et al. eLearning resources to supplement postgraduate neurosurgery training. Acta Neurochir (Wien). 2017;159(2):325-337.

29. Haglund MM, Fuller AT. Global neurosurgery: innovators, strategies, and the way forward. J Neurosurg. 2019;131(4): 993-999.

30. Panwar N, Sharma S, Singh AK. A survey on 5G: The next generation of mobile communication. Phys Commun. 2016; 18(pt 2):64-84.

31. El-Ghandour NMF. Neurosurgical education in Egypt and Africa. Neurosurg Focus. 2020;48(3):E12.

32. Schott NJ, Emerick TD, Metro DG, Sakai T. The cost of resident scholarly activity and its effect on resident clinical experience. Anesth Analg. 2013;117(5):1211-1216.

33. Young Neurosurgeon Education Grant for WFNS Symposia 2018, Kuala Lumpur, Malaysia. Accessed October 22, 2020. https://www.aans.org/en/AANS-E-News/2018/April-2018/ Young-Neurosurgeon-Education-Grant-for-WFNS-Symposia2018-Kuala-Lumpur-Malaysia

34. European Association of Neurosurgical Societies. Accessed October 22, 2020. https://www.eans.org/

35. Iseki H, Masutani Y, Iwahara M, et al. Volumegraph (overlaid three-dimensional image-guided navigation). Clinical application of augmented reality in neurosurgery. Stereotact Funct Neurosurg. 1997;68(1-4 pt 1):18-24.

36. Carolus A, Hesse M, Rudak B, et al. Development of a brain simulator for intracranial targeting: technical note. J Clin Neurosci. 2019;59:378-383.

\section{Disclosures}

The authors report no conflict of interest concerning the materials or methods used in this study or the findings specified in this paper. 


\section{Author Contributions}

Conception and design: El-Ghandour, Soliman. Acquisition of data: Soliman, Ezzat, Zaazoue, Gonzalez-Lopez. Analysis and interpretation of data: Soliman, Jhawar. Drafting the article:

El-Ghandour, Soliman, Jhawar. Critically revising the article: all authors. Reviewed submitted version of manuscript: all authors. Approved the final version of the manuscript on behalf of all authors: Soliman. Statistical analysis: Soliman. Administrative/ technical/material support: El-Ghandour. Study supervision: El-Ghandour, Soliman, Jhawar.

\section{Correspondence}

Mohamed A. R. Soliman: Faculty of Medicine, Cairo University, Cairo,Egypt.moh.ar.sol@kasralainy.edu.eg. 